\title{
Trypan blue removal from water with zein sorbents and laccase
}

\author{
Tatianna Marshall ${ }^{1} \cdot$ Kristine Lamont $^{1} \cdot$ Alejandro G. Marangoni $^{2} \cdot$ Loong-Tak Lim $^{2} \cdot$ Xiuju Wang $^{2} \cdot$ Erica Pensini $^{1}$
}

Received: 4 July 2020 / Accepted: 29 December 2020 / Published online: 7 January 2021

(C) The Author(s) 2021 OPEN

\begin{abstract}
Zein-based materials were used to remove Trypan blue from water under flow conditions and in batch tests. In flow tests, zein dissolved at $\mathrm{pH}=13$ was injected in sand columns and subsequently coagulated with $\mathrm{CaCl}_{2}$, to create an adsorbent filter which removed over $99 \%$ of Trypan blue. Batch tests were conducted using zein powder, zein dissolved at $\mathrm{pH}=13$ and coagulated with $\mathrm{CaCl}_{2}, \mathrm{Fe}_{2} \mathrm{Cl}_{3}$ or citric acid, and zein dissolved in ethanol and then coagulated with water. The highest Trypan blue removal was achieved with zein powder (4000 mg Trypan blue/kg sorbent, as determined through spectrophotometry), followed by zein coagulated with $\mathrm{Fe}_{2} \mathrm{Cl}_{3}$ (500 mg Trypan blue/kg sorbent) and with other salts (140 mg Trypan blue/kg sorbent). Differences in the sorption efficiency are attributed to differences in the surface area. The sorption isotherm of Trypan blue onto zein-based sorbents was a Type II isotherm, suggesting physisorption. Desorption of Trypan blue was limited when zein-based coagulated sorbents were immersed in pure water. Trypan blue could be degraded by free laccase in water, as determined through spectrophotometry and electrospray ionization mass spectroscopy (ESI-MS). Trypan blue could also be degraded by laccase when zein-based laccase-containing sorbents were prepared at $\mathrm{pH}=10$, using $\mathrm{Fe}_{2} \mathrm{Cl}_{3}$ as coagulant.
\end{abstract}

\section{Graphic abstract}

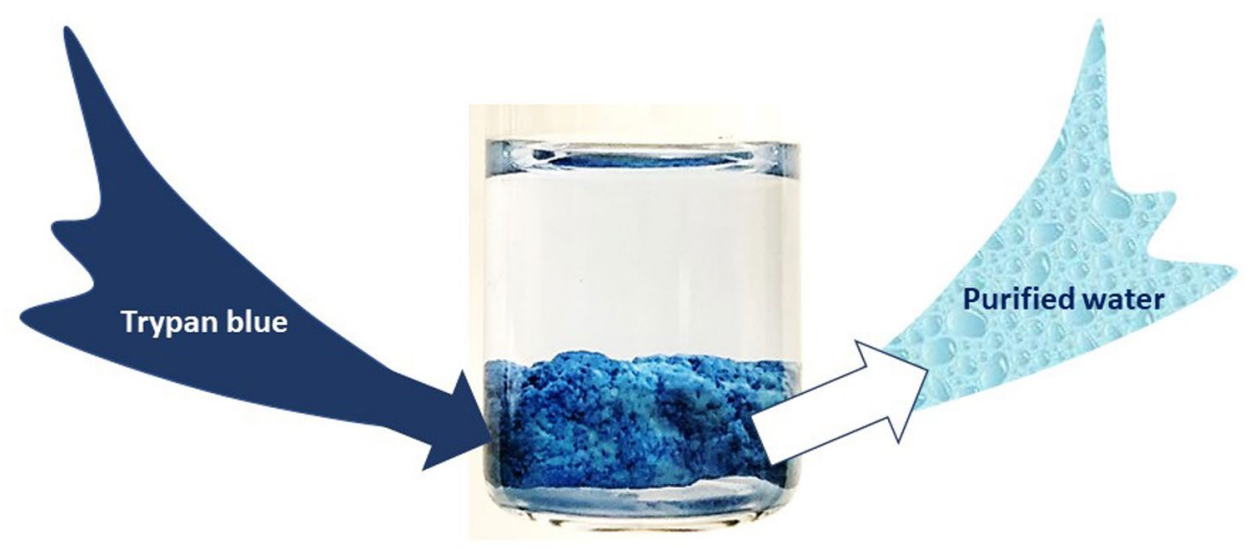

Keywords Sorption $\cdot$ Dye $\cdot$ Trypan blue $\cdot$ Water treatment $\cdot$ Zein $\cdot$ Laccase

Supplementary information The online version contains supplementary material available at https://doi.org/10.1007/s42452-020-04107 $-w$.

Erica Pensini, epensini@uoguelph.ca | 'School of Engineering, University of Guelph, 50 Stone Road East, Guelph, ON N1G 2W1, Canada. ${ }^{2}$ Food Science Department, University of Guelph, 50 Stone Road East, Guelph, ON N1G 2W1, Canada. 


\section{Introduction}

Pollution from industrial processes has recently become a significant worldwide concern [1]. The range of pollutants released into the environment is broad and includes dyes. Dyes are used in the textile industry [2] and in other industries [3], including paper printing, color photography, pharmaceutical, food, cosmetic, and leather industries [4]. Despite their widespread use, dyes are toxic to humans and to the environment. Studies have for instance demonstrated the toxicity of azo dyes, anthraquinone and other dyes [5, 6]. Trypan blue is an azo dye used for biological staining [7], and its toxicity is known. Trypan blue is a teratogen [8], and it can harm the human eye [9]. In addition to their toxicity, when dyes are released in water bodies, they reduce light penetration in water, and they prevent oxygen ingress and increase biochemical oxygen demand [4]. Since dyes are clearly detectable, the aesthetic damage is also of concern [4]. Although industrial effluents should receive treatment prior to discharge, dyes are still being released in the environment [4]. Azo dyes represent approximately half of all dyes used, and they are the largest group of synthetic colorants released into the environment [4].

Previous studies successfully removed different dyes with reverse osmosis [10], with coagulants and flocculants [11], oxidizing agents and Fenton's reagents [12], ozonation and electrochemical methods [13], photocatalysis [14], sonolysis [15], biological methods using fungi and aerobic and anaerobic bacteria [16], sorption and ionic exchange [17].

Different sorbents have been proposed for the removal of dyes from water, including sulfuric acid treated sawdust [18], apple pomace and wheat straw [19], immobilized fungi [20], activated carbon, bagasse, husk, date pits, corncob, pinewood and pith [21], and sunflower stalks (used to remove direct blue dye) [16]. Nanoparticles have also been used for the removal of dyes, including $\mathrm{TiO}_{2}$ nanoparticles (which have been investigated for their sorption capacity and photocatalytic efficiency [22]) and hollow zein nanoparticles for the removal of reactive blue [23]. Polyvinyl alcohol membranes containing scleroglucan, cellulose microfibers, or zein have been used for the removal of crystal violet [24]. Zein is a degradable, inexpensive, by-product of corn, and it is therefore an attractive material for environmental applications [25]. Moreover, white rot fungi, which produce the enzyme laccase, can effectively decolorize dye wastewater [26]. Enzymes, and specifically the fungal enzyme laccase, have been used to decolorize and detoxify water polluted with different types of dyes
[27-29], including Trypan blue [30]. Laccases are coppercontaining oxidoreductases, which can complete one electron oxidation of diverse environmental contaminants [31], including phenolic compounds such as pesticides [32] and furan aldehydes [33], in addition to dyes. Enzymes used for decolorization can be either dispersed in water or immobilized, for instance on modified sand [27]. While both fungal biomass and free laccase can remove Trypan blue from water, a thermokinetic study found that decolorization reactions were spontaneous in nature over a wider temperature range for free laccase than for those with fungal biomass [34]. These results demonstrate the ability of free laccase to withstand large fluctuations in temperature without affecting reaction spontaneity [34]. Some studies have used immobilized laccase to treat dyes or other contaminants. Immobilization scaffolds include chitosan-based materials [35], polyamide/chitosan nanofibers [36], and zein/polyurethane materials [32]. Laccase was also immobilized on zein fibers, used to produce temperature indicators [37]. Laccase immobilization on chitosan and polyamide/chitosan nanofibers was achieved using glutaraldehyde [35, 36].

While Reactive Blue 19 has been sorbed onto nylon-zein fibers [38], zein was not used before for the removal of Trypan blue from water. The effectiveness of laccase in degrading Trypan blue pre-sorbed onto zein sorbents was also not investigated in previous studies. Our study addresses the current gaps by investigating removal of Trypan blue from water using zein sorbents under noflow and continuous stirring conditions (batch tests), and by analyzing the effectiveness of laccase in degrading Trypan blue sorbed onto zein sorbents. These conditions are for instance found in industrial treatment facilities or in engineered water collection ponds. Finally, our study investigates the removal of dyes from water under flow conditions, using a sand column mimicking sandy aquifers. In flow tests, zein sorbent materials were obtained by injecting dissolved zein in a soil column, and subsequently solidifying it, to create a filtering medium. These injectable filtering materials can be located around water bodies such as contaminated lakes, rivers or canals. These filters can protect aquifers recharged from the surface water bodies, by cleaning surface waters flowing into the subsurface.

\section{Materials and methods}

\subsection{Materials}

Zein (purified), $\mathrm{NaOH}$ (pellets, $95-100 \%$, SpectrumTM), $\mathrm{CaCl}_{2} \cdot 2 \mathrm{H}_{2} \mathrm{O}$ (reagent grade), $\mathrm{Fe}_{2} \mathrm{Cl}_{3} \cdot 2 \mathrm{H}_{2} \mathrm{O}$ (reagent grade), 
citric acid (anhydrous, food grade), Trypan blue (ACROS organics), and ethanol anhydrous (EtOH) (95\%) were purchased from Fisher Scientific (Canada). Laccase (from Trametes versicolor) was purchased from Sigma-Aldrich. Antiskid sand (Charbonneau Floral Ltd., Canada) was purchased from a local market. Deionized (DI) water was utilized in all tests conducted.

\subsection{Preparation of zein sorbents for batch tests with Trypan blue}

Zein sorbents used for Trypan blue removal were prepared using four methods. In the first method, they were prepared by solubilizing $33 \mathrm{~g} / \mathrm{L}$ of zein in $\mathrm{DI}$ water at $\mathrm{pH}=13$ and then coagulating it using different coagulants: (1) $\mathrm{CaCl}_{2}$; (2) $\mathrm{Fe}_{2} \mathrm{Cl}_{3}$; (3) citric acid. Different coagulants were tested because they could potentially affect the electrostatic charge of the sorbents and hence their effectiveness in removing Trypan blue. The final concentrations of $\mathrm{CaCl}_{2}$ and $\mathrm{Fe}_{2} \mathrm{Cl}_{3}$ were $0.07 \mathrm{M}$ (and stock solutions had $2 \mathrm{M}$ concentrations). Stock solutions of citric acid had a concentration of $50 \%$ (weight based) and were added to zein solutions to obtain a final citric acid concentration of $33 \mathrm{~g} / \mathrm{L}$ of water. In the second method, laccase $\left(7 \cdot 10^{-2} \mathrm{~g} / \mathrm{L}\right)$ was incorporated in part of the zein samples coagulated with $\mathrm{CaCl}_{2}$, by adding it to zein solutions at $\mathrm{pH}=13$ before the coagulation step with $\mathrm{CaCl}_{2}$. In the third method zein sorbents were prepared using $15 \mathrm{~g} / \mathrm{L}$ of zein, first dissolved at $\mathrm{pH}=13$, before lowering the $\mathrm{pH}$ to $\mathrm{pH}=10$. Laccase was subsequently added at $0.35 \mathrm{~g} / \mathrm{L}$, before solidifying the sorbents with $\mathrm{Fe}_{2} \mathrm{Cl}_{3}$ (to obtain a $0.1 \mathrm{M} \mathrm{Fe}_{2} \mathrm{Cl}_{3}$ ). This method was used in our previous study [39]. In the fourth method zein was dissolved in ethanol $(200 \mathrm{~g} / \mathrm{L})$ and coagulated by adding DI water (to obtain a $20 \%$ ethanol, $80 \%$ water mixture). When using these concentrations, zein-based materials formed a cohesive mass, and will be referred to as "coagulated." Zein sorbents prepared with these four methods were rinsed with DI water and used for Trypan blue removal in batch tests immediately after preparation. Zein powder was also used without further treatment for the removal of Trypan blue from water. In all instances, the $\mathrm{pH}$ was adjusted with $\mathrm{NaOH}$ and $\mathrm{HCl}$.

\subsection{Electrospray ionization mass spectrometry (ESI-MS)}

Trypan blue samples treated with either free laccase in DI water (38 mg/L of Trypan blue and $250 \mathrm{mg} / \mathrm{L}$ laccase) or laccase in $0.5 \mathrm{M} \mathrm{Fe}_{2} \mathrm{Cl}_{3}$ solutions ( $38 \mathrm{mg} / \mathrm{L}$ of Trypan blue) were analyzed using a Thermo LCQ Fleet Ultimate 3000 LC-MS and Xcalibur software. Tests conducted with $\mathrm{Fe}_{2} \mathrm{Cl}_{3}$ solution were aimed at understanding the effect of iron ions on Trypan blue degradation by laccase, because
$\mathrm{Fe}_{2} \mathrm{Cl}_{3}$ was used as a coagulant for zein sorbents (Sect. 2.2). The $0.5 \mathrm{M} \mathrm{Fe}_{2} \mathrm{Cl}_{3}$ solution concentration was selected because it was well above the concentration used to make zein sorbents $(0.07 \mathrm{M})$, and it would hence allow clearly noticing any effect of iron on Trypan blue degradation. Samples were directly analyzed by ESI-MS, bypassing the liquid chromatography column. Trypan blue samples without laccase or $\mathrm{Fe}_{2} \mathrm{Cl}_{3}$ were also analyzed for comparison. All samples were diluted with DI water and analyzed at $\mathrm{pH}=11$ (adjusted with $\mathrm{NaOH}$ ). This $\mathrm{pH}$ was used to ensure that laccase could remain active when sorbents were prepared at alkaline $\mathrm{pH}$.

\subsection{Trypan blue removal from water in batch tests: sorption, desorption and enzymatic degradation}

Batch tests were conducted at room temperature $\left(21^{\circ} \mathrm{C}\right)$ and at $\mathrm{pH}=6$ to test the kinetics of Trypan blue removal from water with either free laccase or with zein sorbents. In tests conducted with free laccase, laccase $(125 \mathrm{mg} / \mathrm{L})$ was added to Trypan blue solutions in DI water $(19 \mathrm{mg} / \mathrm{L})$. Tests were also conducted using zein sorbents with and without laccase, by immersing the sorbents in Trypan blue solutions under either quiescent conditions or continuous mixing (using a magnetic stir bar). Trypan blue concentrations were then monitored over time for a total of either $96 \mathrm{~h}$ (4 days, under quiescent conditions) or $24 \mathrm{~h}$ (under continuous mixing conditions), and determined using a Hach spectrophotometer at $605 \mathrm{~nm}$ wavelength. A separate set of batch tests were conducted at $21{ }^{\circ} \mathrm{C}$ to determine the sorption isotherms with zein-based sorbents coagulated with $\mathrm{CaCl}_{2}$ under either quiescent conditions or continuous mixing. Desorption tests were conducted by immersing zein sorbents used in $24 \mathrm{~h}$ sorption tests in $\mathrm{DI}$ water, and analyzing Trypan blue concentrations after $24 \mathrm{~h}$ under either quiescent conditions or continuous mixing.

\subsection{Trypan blue filtration through zein sorbents injected into sand (flow tests)}

Zein $(33 \mathrm{~g} / \mathrm{L})$ was dissolved in DI water at $\mathrm{pH}=13$. Zein solution $(5 \mathrm{~mL})$ was injected on a sand column $(6 \mathrm{~mL})$, obtained using a Falcon tube pierced at the bottom. Zein was then solidified by injecting $0.5 \mathrm{~mL}$ of $2 \mathrm{M}$ solution of $\mathrm{CaCl}_{2} \cdot 2 \mathrm{H}_{2} \mathrm{O}$ on top of the column. The column was then flushed with $2 \mathrm{~mL}$ of $19 \mathrm{mg} / \mathrm{L}$ Trypan blue solution, without collecting water samples exiting the sand column (because they contained zein residuals). Trypan blue $(19 \mathrm{mg} / \mathrm{L}$ ) was then added to the column again and the water samples were collected at the outlet of the sand column, to determine the reduction in Trypan blue concentration. This process was repeated six times, using 
$3 \mathrm{~mL}$ of Trypan blue solution each time to the column, and analyzing the concentration reduction after each addition. Each water sample was analyzed using a Hach spectrophotometer, at a $605 \mathrm{~nm}$ wavelength.

\subsection{Zeta potential measurements}

Zeta potential measurements were conducted at $23^{\circ} \mathrm{C}$ with a Malvern zetasizer on zein particles formed by adding $\mathrm{CaCl}_{2}\left(7 \times 10^{-2} \mathrm{M}\right), \mathrm{Fe}_{2} \mathrm{Cl}_{3}\left(10^{-2} \mathrm{M}\right)$ and citric acid $(33 \mathrm{~g} / \mathrm{L}$ of water) to $200 \mathrm{mg} / \mathrm{L}$ zein solutions at $\mathrm{pH}=13$ (adjusted with $\mathrm{NaOH}$ ). The concentration of $\mathrm{Fe}_{2} \mathrm{Cl}_{3}$ was kept low to control the formation of large flocs at basic $\mathrm{pH}$. Particles were also produced by adding $20 \mathrm{mg}$ of zein in $1 \mathrm{~mL}$ of ethanol, and subsequently diluting with $200 \mathrm{~mL}$ using DI water. The zeta potential of particles prepared with this method should be similar to the zeta potential of zein sorbent materials (which cannot be analyzed using a zetasizer due to their large size). Measurements were conducted with and without Trypan blue in solution $(0.7 \mathrm{mg} / \mathrm{L})$, to gain insights regarding the effect of electrostatic forces on Trypan blue sorption onto zein. The refractive index used was 1.45 for zein particles and 1.33 for water, as previously described $[25,40]$.

\section{Results and discussion}

Trypan blue was sorbed with either zein powder, or with coagulated zein-based sorbents, without laccase. Coagulation of zein with salts was previously reported [25]. Removal efficiencies of zein sorbents in sorbing Trypan blue from water in batch tests conducted under quiescent conditions over $24 \mathrm{~h}$ were determined using spectrophotometry and a calibration curve (Supporting Information,

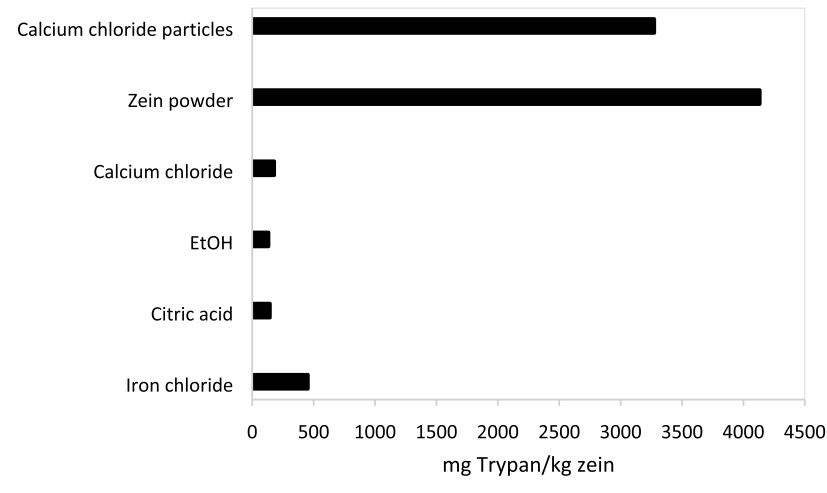

Fig. 1 Trypan blue sorption onto zein sorbents after $24 \mathrm{~h}$ sorption under quiescent conditions, as determined using spectrophotometry. The initial Trypan blue concentration in water was $19 \mathrm{mg} / \mathrm{L}$. The standard deviation between measurements was below $1 \mathrm{mg}$ Trypan/kg zein
Fig. Sl.1) and are given in Fig. 1. Sorption was most significant with zein powder, likely due to its high surface area compared to zein-based sorbents coagulated with $\mathrm{CaCl}_{2}, \mathrm{Fe}_{2} \mathrm{Cl}_{3}$ or citric acid, or obtained by adding water to zein solutions in ethanol (Figure 2). While more effective in removing Trypan blue, zein powder may be more challenging to recover from water than coagulated zein-based sorbents. Future research should focus on increasing the surface area of zein-based sorbents, while ensuring that they can be easily removed from water after treatment or used under flow conditions.

The coagulant used to prepare lumped zein sorbents affected their sorption efficiency, which increased in the following order: $\mathrm{Fe}_{2} \mathrm{Cl}_{3}>\mathrm{CaCl}_{2} \cong$ citric acid $\cong \mathrm{EtOH}$ (Fig. 1). Zeta potential measurements were conducted on zein prepared at low zein concentrations, in the native solutions in which they were prepared, to gain insights regarding the effect of electrostatic interactions on Trypan blue sorption onto zein-based sorbents. Zeta potential measurements showed that zein particles obtained by adding $\mathrm{CaCl}_{2}$ to zein solution at $\mathrm{pH}=13$ were approximately neutral, in agreement with our previous study [25]. It is likely that coagulated zein-based sorbents were positively charged at $\mathrm{pH}=6$, at which sorption experiments were conducted after rinsing coagulated zein sorbents. At $\mathrm{pH}=13$, the zeta potential of zein particles obtained with $\mathrm{Fe}_{2} \mathrm{Cl}_{3}$ was $\cong-16 \mathrm{mV}(\mathrm{pH} \cong 12)$, whereas it was $\cong+11 \mathrm{mV}$ and $\cong+18 \mathrm{mV}$ when particles were prepared with citric acid $(\mathrm{pH} \cong 3)$ and $\mathrm{EtOH}(\mathrm{pH} \cong 6)$, respectively. Iron likely dissociated and then formed iron oxides and hydroxides in water, the point of zero charge of which is at approximately $\mathrm{pH}=8-10$ [41]. Above the point of zero charge, iron present in the zein particles was likely responsible for their negative electric charge, whereas at $\mathrm{pH}=6$ iron oxides should be positively charged. A positive zeta potential was previously reported for zein particles produced using ethanol and water, and attributed to amino acid ionization [42]. Finally, the low $\mathrm{pH}$ measured with citric acid may account for the positive zeta potential of zein particles. Trypan blue is negatively charged, due to the hydroxyl groups and the $\mathrm{SO}_{3}{ }^{-}$groups. Electrostatic interactions may have contributed to physisorption of Trypan blue onto zein sorbents at $\mathrm{pH}=6$. The effectiveness of zein-based sorbents coagulated with $\mathrm{Fe}_{2} \mathrm{Cl}_{3}$ suggests a specific affinity of Trypan blue for iron. Sorption and reduction of azo dyes on iron and iron-containing materials was previously reported. For instance, nanoscale zero-valent iron particles were used to remove the azo dye AB24 from water through reduction at $\mathrm{pH}=9$ [43]. The azo dye Congo red was sorbed onto iron composite nanoparticles [44]. Other azo dyes, both anionic and cationic, including Direct Blue 71, Acid Blue 40 and Basic Violet 16, were sorbed onto iron-based waterworks sludge [45]. These published results suggest 
Fig. 2 Example of compacted zein-based sorbent prepared with zein and $\mathrm{CaCl}_{2}$ (left) and optical microscopy image of zein powder (right)

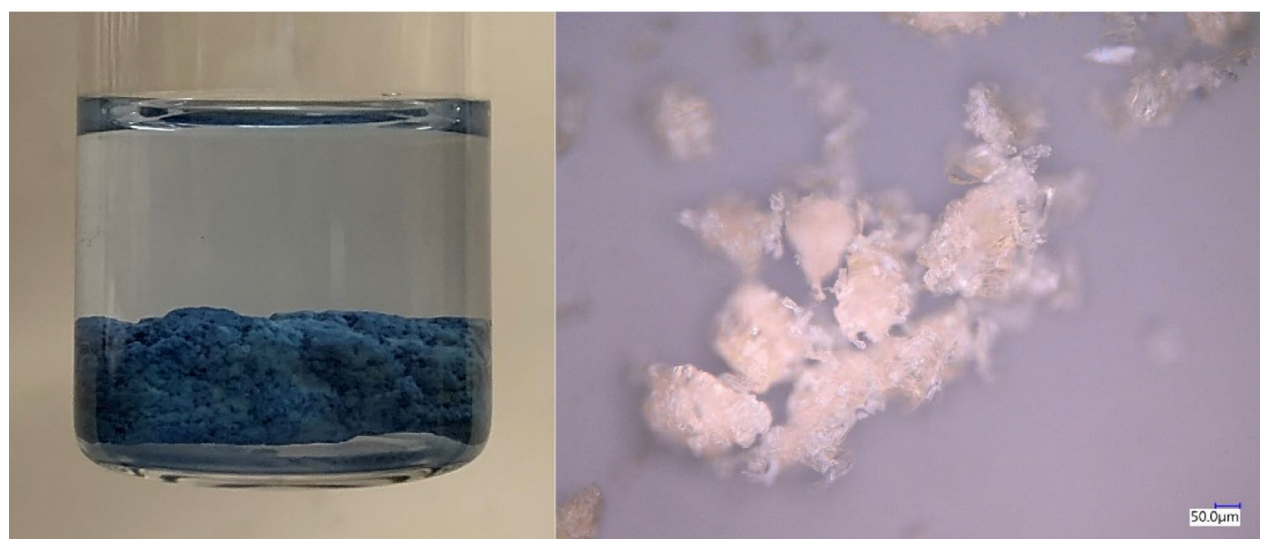

that electrostatic interactions did not control sorption of dye onto iron sorbents coagulated with $\mathrm{Fe}_{2} \mathrm{Cl}_{3}$, since sorption onto iron compounds was previously observed for both anionic and cationic azo dyes. While more effective in sorbing Trypan blue, lumped zein sorbents coagulated with $\mathrm{Fe}_{2} \mathrm{Cl}_{3}$ released small quantities of iron, as determined with the naked eye based on the discoloration of water. Therefore, the use of $\mathrm{CaCl}_{2}$ could be preferred to $\mathrm{Fe}_{2} \mathrm{Cl}_{3}$ for zein coagulation. It is also speculated that hydrophobic interactions between the hydrophobic portions of zein and the aromatic groups of Trypan blue contributed to sorption. Some authors hypothesized hydrogen bonding between selected azo dyes onto zein (rather than physisorption). For instance, some studies suggested hydrogen bonding between the $\mathrm{OH}$ and $\mathrm{NH}_{2}$ groups of the azo dye Reactive Blue 19 dye and the $\mathrm{N}-\mathrm{H}$ groups of zein [23], and hydrogen bonding has also been hypothesized between reactive black dye onto zein nanofibers [46].

Sorption of Trypan blue onto zein sorbents coagulated with $\mathrm{CaCl}_{2}$ occurred gradually under quiescent conditions, as shown in Fig. 3. The kinetics of Trypan blue removal could have been due to either mass transfer limitations or to the sorption mechanisms. Experiments under stirring

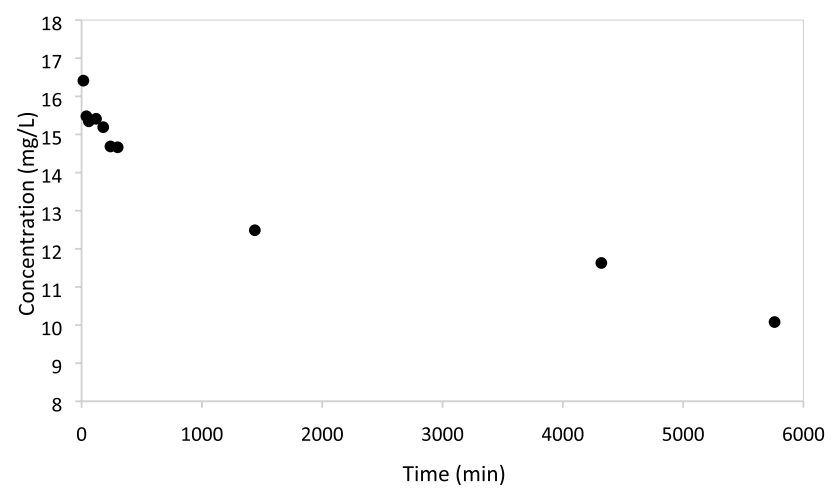

Fig. 3 Sorption of Trypan blue ( $19 \mathrm{mg} / \mathrm{L}$ ) onto zein coagulated with $\mathrm{CaCl}_{2}$ over time under quiescent conditions. The sorbent mass used was $0.1 \mathrm{~kg} / \mathrm{L}$ conditions were conducted to assess which factor controlled the kinetics of Trypan blue removal. Under stirring conditions, the concentration of Trypan blue decreased more rapidly, and was reduced from 19 to $12 \mathrm{mg} / \mathrm{L}$ after $300 \mathrm{~min}$ and finally to approximately $10 \mathrm{mg} / \mathrm{L}$ after $24 \mathrm{~h}$. These results indicate that mass transfer could be promoted by mixing, improving the Trypan blue removal efficiency. Nonetheless, both under quiescent and continuous mixing conditions, sorption was not instantaneous. Chemisorption generally occurs instantaneously [47]. Therefore, the data suggest that hydrophobic interactions (rather than stronger bonds such as hydrogen bonds) controlled sorption of Trypan blue onto zein sorbents coagulated with $\mathrm{CaCl}_{2}$.

The sorption isotherm measured for Trypan blue sorption onto zein sorbents coagulated with $\mathrm{CaCl}_{2}$ after $24 \mathrm{~h}$ under stirring conditions had the characteristic $s$ shape of a Type II sorption isotherm (Fig. 4). Type II isotherms are observed exclusively for physisorption [48], supporting the hypothesis of hydrophobic interactions rather than stronger chemical or hydrogen bonding between zein Trypan blue. It is noted that after $24 \mathrm{~h}$ sorption was lower

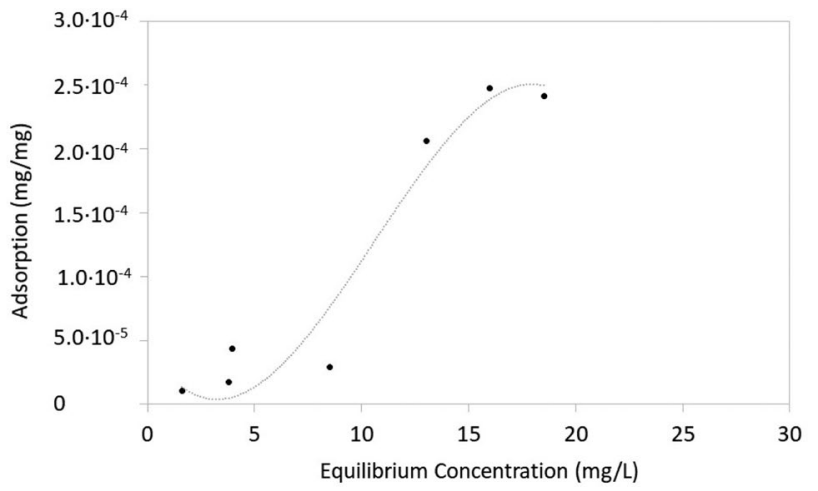

Fig. 4 Sorption isotherm of Trypan blue onto zein coagulated with $\mathrm{CaCl}_{2}$. The curves were measured after $24 \mathrm{~h}$ sorption, under continuous stirring conditions 

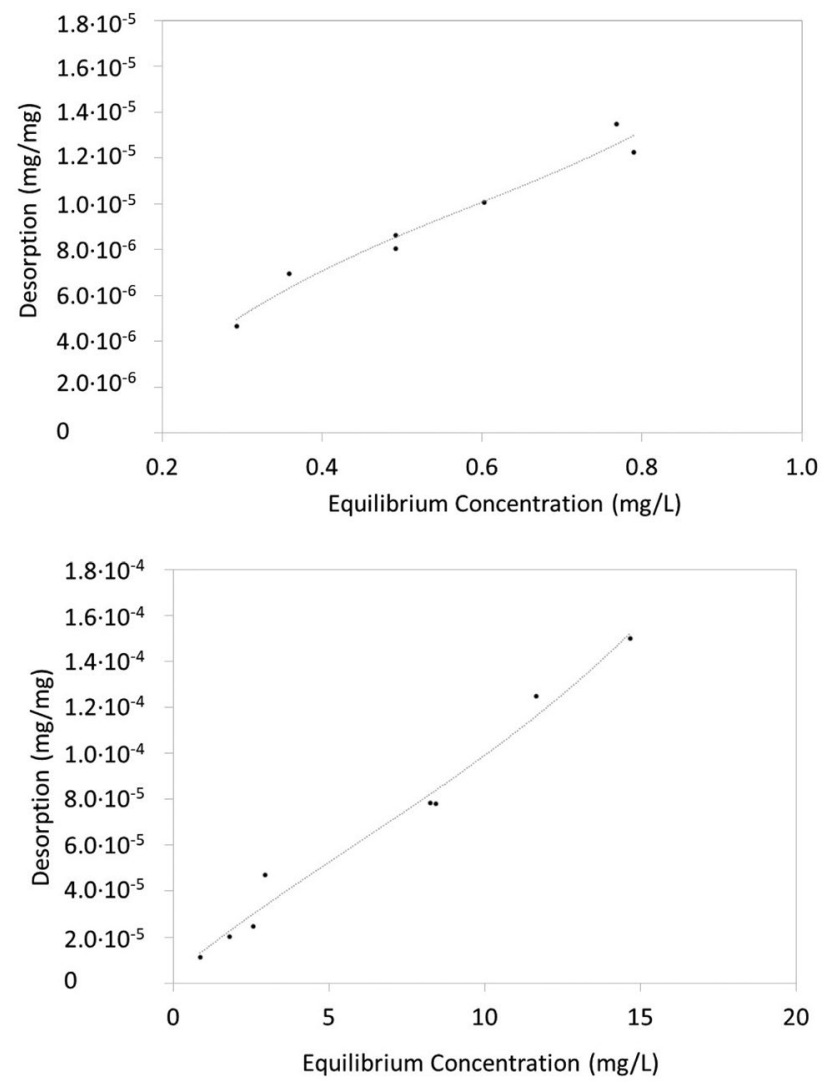

Fig. 5 Desorption isotherm of Trypan blue from zein coagulated with $\mathrm{CaCl}_{2}$. Sorbents were immersed in DI water following $24 \mathrm{~h}$ sorption and equilibrated for an additional $24 \mathrm{~h}$ in DI water under quiescent conditions (top) or under mixing conditions (bottom)

without stirring. This result confirms that stirring promoted mass transfer and hence Trypan blue removal (as discussed above). Sorption after $24 \mathrm{~h}$ under quiescent conditions is shown in Fig. Sl. 2 (Supporting Information file).

Physisorption was confirmed by the fact that Trypan blue could desorb from zein-based sorbents coagulated with $\mathrm{CaCl}_{2}$ upon immersion in DI water under either quiescent or continuous stirring conditions, although desorption was limited over a period of $24 \mathrm{~h}$ (Fig. 5). It is noted that the sorption isotherm was obtained using Trypan blue concentrations in a range from approximately $1-38 \mathrm{mg} / \mathrm{L}$. Investigating larger concentration ranges should be the objective of future research.

Finally, Trypan blue removal from water under flow conditions was tested, using zein filters obtained by injecting zein solutions in sand columns and subsequently coagulating them with $\mathrm{CaCl}_{2}$. After initially passing an aliquot of $3 \mathrm{~mL}$ through the zein filters, the concentration of Trypan blue decreased by over $99.5 \%$ (from a starting concentration of $19 \mathrm{mg} / \mathrm{L})$. When additional aliquots of Trypan blue solutions were injected ( $3 \mathrm{~mL}$ each, up to a total of 6 aliquots), the concentration of Trypan blue decreased

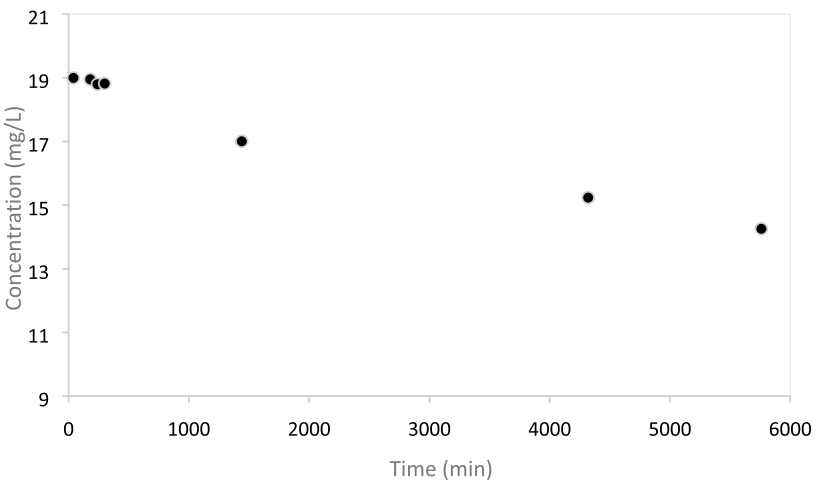

Fig. 6 Concentration of Trypan blue in water, following degradation with $125 \mathrm{mg} / \mathrm{L}$ of laccase at neutral $\mathrm{pH}$. The initial concentration of Trypan blue in water was $19 \mathrm{mg} / \mathrm{L}$

by $94.5 \%$ or more for each aliquot. Zein filters produced with a single injection of zein reduced flow by approximately $63 \%$. Our previous study demonstrated that layered injection of zein could create barriers that reduced flow by $\approx 96 \%$ [25]. Here, the goal is not however to fully impede flow. It is envisioned that zein filters could be injected around surface water bodies contaminated by Trypan blue dye, allowing aquifer recharge with decontaminated water.

Previous studies successfully removed different dyes with diverse methods, including sorption and ionic exchange [17]. However, sorbents previously developed could not be produced in situ, for instance around river beds or lakes polluted with dyes. This is the first study in which sorbents for dye removal were produced in situ (at the lab scale) by injection of zein solutions inside a geological medium, followed by zein solidification using salt solutions.

It is noted that typical textile wastewater contains impurities such as acids, alkalis, salts, and metal ions (ex. $\mathrm{Na}^{+}$, $\left.\mathrm{K}^{+}, \mathrm{Cu}^{2+}, \mathrm{Ca}^{2+}, \mathrm{Cr}^{3+}\right)[49]$. The presence of these impurities, especially cations, can increase the ionic strength, significantly impacting the adsorption of dyes [50]. Future work should then investigate the effect of wastewater impurities on Trypan blue sorption onto zein filters.

While sorbents can remove Trypan blue from water, they do not degrade it. Laccase progressively reduced Trypan blue concentrations in water at neutral $\mathrm{pH}$, as determined with spectrophotometry (Fig. 6). Trypan blue reduction was $25 \%$ in $96 \mathrm{~h}$. Trypan blue degradation was also evident based on observations with the naked eye, which showed first a transition from blue to purple and then a decrease in the color intensity.

Previous studies successfully used free laccase to decolorize Trypan blue solutions [30, 34, 51]. The laccasemediated degradation of azo dyes is attributed to a twostep process, in which one electron is abstracted from the 
phenolic/naphtholic ring to form a phenoxy radical, followed by the abstraction of a second electron to form an aromatic cation stabilized by electron-donating groups in the ring [30]. ESI-MS analyses indicated that laccase could also degrade Trypan blue at alkaline $\mathrm{pH}(\mathrm{pH}=11)$, in either DI water or in $0.5 \mathrm{M} \mathrm{Fe}_{2} \mathrm{Cl}_{3}$ solutions, as evident from the appearance of new peaks after either treatment for $24 \mathrm{~h}$ (Figs. SI.3-SI.5, Supporting Information). Possible characteristic peaks for Trypan blue at $\mathrm{pH}=11$ were identified at $295,335,401,441$, and $454 \mathrm{~m} / \mathrm{z}$. After treatment with laccase, the Trypan blue characteristic peaks remained with the addition of new major peaks at $507,547,613,719,825$, and $931 \mathrm{~m} / \mathrm{z}$. The clear appearance of new m/z peaks suggests degradation of Trypan blue. After treatment with laccase in $\mathrm{Fe}_{2} \mathrm{Cl}_{3}$, solutions, the Trypan blue characteristic peaks again remained, along with identical $\mathrm{m} / \mathrm{z}$ values for newly introduced peaks. Identical $\mathrm{m} / \mathrm{z}$ values of Trypan blue with laccase and Trypan blue in $\mathrm{Fe}_{2} \mathrm{Cl}_{3}$ solutions could propose that possible degradation pathways are similar under both conditions.

Trypan blue degradation by laccase at alkaline $\mathrm{pH}$ and in the presence of iron chloride indicates that it would be possible to incorporate laccase in zein-based sorbents coagulated with $\mathrm{Fe}_{2} \mathrm{Cl}_{3}$ and prepared at alkaline $\mathrm{pH}$ to degrade Trypan blue (as will be discussed shortly here below). It is however noted that laccase activity is $\mathrm{pH}$ dependent, as we determined in our previous study [39]. This study demonstrated that free laccase activity was optimal at $\mathrm{pH} \approx 5$, but it remained active up to $\mathrm{pH} \approx 10-11$. This study also showed that iron promoted binding of laccase onto zein and its incorporation into zein sorbents coagulated with $\mathrm{Fe}_{2} \mathrm{Cl}_{3}$ [39]. Importantly, this study also shows that laccase retained its activity when it was incorporated inside zein sorbents coagulated with $\mathrm{Fe}_{2} \mathrm{Cl}_{3}$ and prepared at $\mathrm{pH}=10$ [39].

Incorporating laccase inside zein sorbents is advantageous. Currently, methods have been developed to extract laccase at a lower cost compared to the past $[52,53]$. Nonetheless, embedding laccase in zein sorbents would allow its reuse, hence further decreasing costs. Other methods of removal of dyes could also be relatively inexpensive, such as Fenton's reagents [54] and activated carbon [55]. The advantage of using laccase-containing zein sorbents is that they would allow degradation (dissimilar to materials that can exclusively sorb), while also avoiding the use of chemicals. Laccase was therefore embedded into zein sorbents coagulated with $\mathrm{Fe}_{2} \mathrm{Cl}_{3}$ at $\mathrm{pH}=10$, with the goal of degrading Trypan blue following its sorption onto zein. The purple discoloration of the water indicated Trypan blue degradation, confirming that laccase remained active. Without laccase (sorption only), Trypan blue concentrations (and hence the blue color intensity) decreased (as described above), but the color did not change to purple.

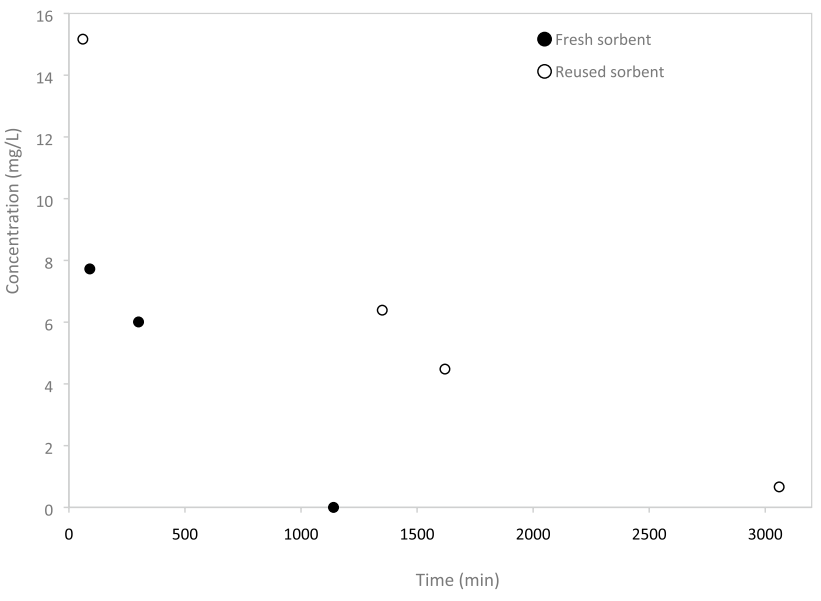

Fig. 7 Removal of Trypan blue with zein sorbents coagulated with $\mathrm{Fe}_{2} \mathrm{Cl}_{3}$ with laccase $(0.12 \mathrm{~g}$ laccase $/ \mathrm{g}$ sorbent). The sorbent mass used was $37 \mathrm{~g} / \mathrm{L}$, and the initial Trypan blue concentration was $19 \mathrm{mg} / \mathrm{L}$

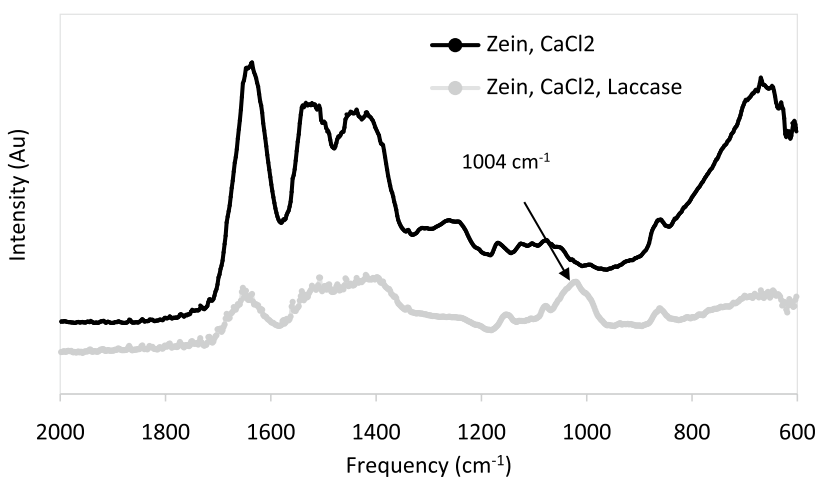

Fig. 8 Zein sorbents coagulated with $\mathrm{CaCl}_{2}$ with and without laccase

The surface of the zein sorbents in which laccase was embedded also turned purple upon exposure to Trypan blue (Fig. SI.6, Supporting Information). Importantly, the Trypan concentrations in water decreased more significantly when using sorbents containing laccase, even after sorbents were reused twice (Fig. 7).

The advantage of using zein-based sorbents containing laccase is that dye removal using sorbents is operationally simple. Also, incorporating laccase would allow sorbent reuse, because laccase degrades Trypan blue. Importantly, the proposed sorbents could be used to produce filters in situ, for instance around river beds or lakes polluted with dyes. Sorbents proposed in previous studies for dye removal were not applicable for in situ applications, as discussed above.

It is noted that $\mathrm{CaCl}_{2}$ was not an effective coagulant at $\mathrm{pH}=10$. When zein sorbents were prepared at $\mathrm{pH}=13$ and effectively coagulated with $\mathrm{CaCl}_{2}$, laccase could be 
incorporated inside the sorbents. The successful incorporation of laccase in zein sorbents was verified with FT-IR, which showed a distinctive peak at $1031 \mathrm{~cm}^{-1}$ in the spectra of zein sorbents containing laccase (Fig. 8). This peak is characteristic of $\mathrm{C}-\mathrm{O}-\mathrm{C}$ bonds in laccase $[56,57]$ and was absent in zein sorbents without laccase. However, when zein sorbents were prepared at $\mathrm{pH}=13$ and coagulated with $\mathrm{CaCl}_{2}$, the color of the sorbent surface remained blue (instead of transitioning to purple, as was observed with free laccase). An alternative approach was thus attempted. Trypan blue was initially sorbed onto zein sorbents prepared at $\mathrm{pH}=13$ (without laccase and coagulated with $\left(\mathrm{CCl}_{2}\right.$ ) and were immersed into a bath of free laccase $(125 \mathrm{mg} / \mathrm{L})$. Once again, the surface of the sorbents remained blue over a period of 11 days (rather than turning purple), indicating that enzymatic degradation of Trypan blue was inhibited. These results suggest that laccase was not able to degrade Trypan blue when it was sorbed onto zein sorbents prepared at $\mathrm{pH}=13$. This is because laccase activity is hindered at very alkaline $\mathrm{pH}$ [39]. As mentioned earlier and as demonstrated in our previous study, laccase activity is optimal at $\mathrm{pH}=5$, but it is nonetheless active at $\mathrm{pH}=10$ [39]. Instead, further raising the $\mathrm{pH}$ to $\mathrm{pH}=13$ renders laccase inactive [39].

\section{Conclusions}

Zein powder and zein-based sorbents were used to remove Trypan blue from water at $21^{\circ} \mathrm{C}$. Part of the zein-based sorbents contained laccase, a dye-degrading enzyme. Zeinbased sorbents without laccase were obtained by coagulating zein dissolved at $\mathrm{pH}=13$ with either $\mathrm{CaCl}_{2}, \mathrm{Fe}_{2} \mathrm{Cl}_{3}$ or citric acid, or by coagulating zein dissolved in ethanol with DI water. Zein powder was the most effective among the sorbents tested, and it sorbed over 4000 mg Trypan blue/ kg sorbent (as determined through spectrophotometry). Removal efficiency was lower with coagulated zein sorbents, likely because of their lower surface area. Trypan blue removal was $500 \mathrm{mg}$ Trypan blue/kg sorbent for sorbents coagulated with $\mathrm{Fe}_{2} \mathrm{Cl}_{3}$ and approximately $140 \mathrm{mg}$ Trypan blue/kg sorbent for all other sorbents. While less effective, coagulated zein-based sorbents are easy to extract from water after being used. Future research should focus on the development of zein sorbents with high surface area, but easy to retrieve from water. The sorption isotherm of Trypan blue onto zein-based sorbents was a Type II isotherm, suggesting physisorption. Trypan blue could desorb from zein-based coagulated sorbents (without laccase) when they were immersed in DI water after sorption, but desorption was limited after $24 \mathrm{~h}$. Sorbents were also produced by injecting zein solutions in geological media and subsequently solidifying them with $\mathrm{CaCl}_{2}$ solutions. This is the first study in which injectable sorbents were formed in situ for the removal of Trypan blue. Spectrophotometry and ESI-MS demonstrated that free laccase degraded Trypan blue in water. Laccase immobilized in zein-based sorbents prepared at $\mathrm{pH}=10$ and coagulated with $\mathrm{Fe}_{2} \mathrm{Cl}_{3}$ was also active and could degrade Trypan blue. Laccasecontaining sorbents were therefore self-cleaning, because the dye was degraded after being absorbed. This is the first study showing the effectiveness of incorporating laccase into zein sorbents for the removal of Trypan blue.

Acknowledgements The research was funded by the Natural Sciences and Engineering Research Council of Canada through a Discovery Grant awarded to Dr. Erica Pensini (No. RGPIN-2018-04636).

Data Availability The data that support the findings of this study are available from the corresponding author upon reasonable request.

\section{Compliance with ethical standards}

Conflict of interest The authors do not have any conflicts of interest to declare.

Open Access This article is licensed under a Creative Commons Attribution 4.0 International License, which permits use, sharing, adaptation, distribution and reproduction in any medium or format, as long as you give appropriate credit to the original author(s) and the source, provide a link to the Creative Commons licence, and indicate if changes were made. The images or other third party material in this article are included in the article's Creative Commons licence, unless indicated otherwise in a credit line to the material. If material is not included in the article's Creative Commons licence and your intended use is not permitted by statutory regulation or exceeds the permitted use, you will need to obtain permission directly from the copyright holder. To view a copy of this licence, visit http://creativecommons .org/licenses/by/4.0/.

\section{References}

1. Chen M, Xu P, Zeng G, Yang C, Huang D, Zhang J (2015) Bioremediation of soils contaminated with polycyclic aromatic hydrocarbons, petroleum, pesticides, chlorophenols and heavy metals by composting: applications, microbes and future research needs. Biotechnol Adv 33:745-755

2. Lim SL, Chu WL, Phang SM (2010) Use of Chlorella vulgaris for bioremediation of textile wastewater. Bioresour Technol 101:7314-7322

3. Ali KA, Qayyum H (2007) Potential of plant polyphenol oxidases in the decolorization and removal of textile and non-textile dyes. J Environ Sci 19:396-402

4. Ali $\mathrm{H}$ (2010) Biodegradation of synthetic dyes-a review. Water Air Soil Pollut 213:251-273

5. Novotný Č, Dias N, Kapanen A, Malachová K, Vándrovcová M, Itävaara M, Lima N (2006) Comparative use of bacterial, algal and protozoan tests to study toxicity of azo-and anthraquinone dyes. Chemosphere 63:1436-1442

6. Khan AA, Husain Q (2007) Decolorization and removal of textile and non-textile dyes from polluted wastewater and 
dyeing effluent by using potato (Solanum tuberosum) soluble and immobilized polyphenol oxidase. Bioresour Technol 98:1012-1019

7. Louis KS, Siegel AC (2011) Cell viability analysis using trypan blue: manual and automated methods. In: Stoddart M (ed) Mammalian cell viability. Humana Press, Totowa, pp 7-12

8. Kim SI, Kim HJ, Lee HJ, Lee K, Hong D, Lim H, Cho K, Jung N, Yi YW (2016) Application of a non-hazardous vital dye for cell counting with automated cell counters. Anal Biochem 492:8-12

9. Gale JS, Proulx AA, Gonder JR, Mao AJ, Hutnik CM (2004) Comparison of the in vitro toxicity of indocyanine green to that of trypan blue in human retinal pigment epithelium cell cultures. Am J Ophthalmol 138:64-69

10. Nataraj SK, Hosamani KM, Aminabhavi TM (2009) Nanofiltration and reverse osmosis thin film composite membrane module for the removal of dye and salts from the simulated mixtures. Desalination 249:12-17

11. Shi B, Li G, Wang D, Feng C, Tang H (2007) Removal of direct dyes by coagulation: the performance of preformed polymeric aluminum species. J Hazard Mater 143:567-574

12. El Haddad M, Regti A, Laamari MR, Mamouni R, Saffaj N (2014) Use of Fenton reagent as advanced oxidative process for removing textile dyes from aqueous solutions. J Mater Environ Sci 5:667-674

13. Szpyrkowicz L, Juzzolino C, Kaul SN (2001) A comparative study on oxidation of disperse dyes by electrochemical process, ozone, hypochlorite and Fenton reagent. Water Res 35:2129-2136

14. Natarajan S, Bajaj HC, Tayade R (2018) Recent advances based on the synergetic effect of adsorption for removal of dyes from waste water using photocatalytic process. J Environ Sci 65:201-222

15. Eren Z, Ince NH (2010) Sonolytic and sonocatalytic degradation of azo dyes by low and high frequency ultrasound. J Hazard Mater 177:1019-1024

16. Gupta VK (2009) Application of low-cost adsorbents for dye removal-a review. J Environ Manag 90:2313-2342

17. Tahir SS, Rauf N (2006) Removal of a cationic dye from aqueous solutions by adsorption onto bentonite clay. Chemosphere 63:1842-1848

18. Garg VK, Gupta R, Yadav AB, Kumar R (2003) Dye removal from aqueous solution by adsorption on treated sawdust. Bioresour Technol 89:121-124

19. Robinson T, Chandran B, Nigam P (2002) Removal of dyes from a synthetic textile dye effluent by biosorption on apple pomace and wheat straw. Water Res 36:2824-2830

20. Couto SR (2009) Dye removal by immobilised fungi. Biotechnol Adv 27:227-235

21. Crini G (2006) Non-conventional low-cost adsorbents for dye removal: a review. Bioresour Technol 97:1061-1085

22. Babitha S, Korrapati PS (2015) $\mathrm{TiO}_{2}$ immobilized zein microspheres: a biocompatible adsorbent for effective dye decolourisation. RSC Adv 5:26475-26481

23. Xu H, Zhang Y, Jiang Q, Reddy N, Yang Y (2013) Biodegradable hollow zein nanoparticles for removal of reactive dyes from wastewater. J Environ Manag 125:33-40

24. Papancea A, Patachia S, Dobritoiu R (2015) Crystal violet dye sorption and transport in/through biobased PVA cryogel membranes. J Appl Polym Sci 132:41838

25. Marshall T, Gravelle A, Marangoni AG, Elsayed A, Pensini E (2020) Zein for hydrocarbon remediation: emulsifier, trapping agent, or both? Colloids Surf A 589:124456

26. Levin L, Papinutti L, Forchiassin F (2004) Evaluation of Argentinean white rot fungi for their ability to produce lignin-modifying enzymes and decolorize industrial dyes. Bioresour Technol 94:169-176
27. Peralta-Zamora P, Pereira CM, Tiburtius ER, Moraes SG, Rosa MA, Minussi RC, Durán N (2003) Decolorization of reactive dyes by immobilized laccase. Appl Catal B 42:131-144

28. Abadulla E, Tzanov T, Costa S, Robra KH, Cavaco-Paulo A, Gübitz GM (2000) Decolorization and detoxification of textile dyes with a laccase from Trametes hirsuta. Appl Environ Microbiol 66:3357-3362

29. Claus H, Faber G, König HJAM (2002) Redox-mediated decolorization of synthetic dyes by fungal laccases. Appl Microbiol Biotechnol 59:672-678

30. Sadhasivam S, Savitha S, Swaminathan K (2009) Redox-mediated decolorization of recalcitrant textile dyes by Trichoderma harzianum WL1 laccase. World J Microbiol Biotechnol 25:1733-1741

31. Bilal M, Rasheed T, Nabeel F, Iqbal HM, Zhao Y (2019) Hazardous contaminants in the environment and their laccase-assisted degradation-a review. J Environ Manag 234:253-264

32. Palvannan T, Saravanakumar T, Unnithan AR, Chung N-J, Kim D-H, Park S-M (2014) Efficient transformation of phenyl urea herbicide chloroxuron by laccase immobilized on zein polyurethane nanofiber. J Mol Catal B 99:156-162

33. Saravanakumar T, Park HS, Mo AY, Choi MS, Kim DH, Park SM (2016) Detoxification of furanic and phenolic lignocellulose derived inhibitors of yeast using laccase immobilized on bacterial cellulosic nanofibers. J Mol Catal B 134:196-205

34. Razak NNA, Annuar MSM (2014) Thermokinetic comparison of trypan blue decolorization by free laccase and fungal biomass. Appl Biochem Biotechnol 172:2932-2944

35. Zheng F, Cui BK, Wu XJ, Meng G, Liu HX, Si J (2016) Immobilization of laccase onto chitosan beads to enhance its capability to degrade synthetic dyes. Int Biodeter Biodegr 110:69-78

36. Maryšková M, Ardao I, García-González CA, Martinová L, Rotková J, Ševců A (2016) Polyamide 6/chitosan nanofibers as support for the immobilization of Trametes versicolor laccase for the elimination of endocrine disrupting chemicals. Enzyme Microbial Technol 89:31-38

37. Jhuang JR, Lin SB, Chen LC, Lou SN, Chen SH, Chen HH (2020) Development of immobilized laccase-based time temperature indicator by electrospinning zein fiber. Food Packag Shelf Life 23:100436

38. Hakro RA, Qureshi UA, Qureshi RF, Mahar RB, Khatri M, Ahmed F, Khatri Z, Kim IS (2018) Efficient removal of reactive blue 19 dye by co-electrospun nanofibers. Preprints 2018070108

39. Marshall T, Marangoni AG, Laredo T, Estepa KM, Corradini MG, Lim LT, Pensini E (2020) Laccase-zein interactions at the airwater interface: reactors on an air bubble and naphthalene removal. Colloids Surf A 607:125518

40. Pan Y, Tikekar RV, Wang MS, Avena-Bustillos RJ, Nitin N (2015) Effect of barrier properties of zein colloidal particles and oilin-water emulsions on oxidative stability of encapsulated bioactive compounds. Food Hydrocoll 43:82-90

41. Pensini E, Sleep BE, Yip CM, O'Carroll D (2013) Forces of interaction between fresh iron particles and iron oxide (magnetite): effect of water chemistry and polymer coatings. Colloids Surf A 433:104-110

42. Dai L, Sun C, Di Wang YG (2016) The interaction between zein and lecithin in ethanol-water solution and characterization of zein-lecithin composite colloidal nanoparticles. PLoS ONE $11: \mathrm{e} 0167172$

43. Lin YT, Weng $\mathrm{CH}$, Chen FY (2008) Effective removal of AB24 dye by nano/micro-size zero-valent iron. Sep Purif Technol 64:26-30

44. Ali I, AL-Othman ZA, Alwarthan A (2016) Molecular uptake of congo red dye from water on iron composite nano particles. J Mol Liq 224:171-176 
45. Kayranli B (2011) Adsorption of textile dyes onto iron based waterworks sludge from aqueous solution; isotherm, kinetic and thermodynamic study. Chem Eng J 173:782-791

46. Qureshi UA, Khatri Z, Ahmed F, Khatri M, Kim IS (2017) Electrospun zein nanofiber as a green and recyclable adsorbent for the removal of reactive black 5 from the aqueous phase. ACS Sustain Chem Eng 5:4340-4351

47. Tran HN, You S-J, Chao H-P (2016) Thermodynamic parameters of cadmium adsorption onto orange peel calculated from various methods: a comparison study. J Environ Chem Eng 4:2671-2682

48. Liu S (2015) Cooperative adsorption on solid surfaces. J Colloid Interface Sci 450:224-238

49. Maurya NS, Mittal AK, Cornel P, Rother E (2006) Biosorption of dyes using dead macro fungi: Effect of dye structure, ionic strength and $\mathrm{pH}$. Bioresour Technol 97:512-521

50. Hu Y, Guo T, Ye X, Li Q, Guo M, Liu H, Wu Z (2013) Dye adsorption by resins: effect of ionic strength on hydrophobic and electrostatic interactions. Chem Eng 228:392-397

51. Baldrian P (2004) Purification and characterization of laccase from the white-rot fungus Daedalea quercina and decolorization of synthetic dyes by the enzyme. Appl Microbiol Biotechnol 63:560-563

52. Niladevi KN, Sukumaran RK, Prema P (2007) Utilization of rice straw for laccase production by Streptomyces psammoticus in solid-state fermentation. J Ind Microbiol Biotechnol 34:665-674
53. Rosales E, Couto SR, Sanromán A (2002) New uses of food waste: application to laccase production by Trametes hirsuta. Biotechnol Lett 24:701-704

54. Lucas MS, Peres JA (2006) Decolorization of the azo dye Reactive Black 5 by Fenton and photo-Fenton oxidation. Dyes Pigments 71:236-244

55. Malik PK (2004) Dye removal from wastewater using activated carbon developed from sawdust: adsorption equilibrium and kinetics. J Hazard Mater 113:81-88

56. Tavares AP, Silva CG, Dražić G, Silva AM, Loureiro JM, Faria JL (2015) Laccase immobilization over multi-walled carbon nanotubes: kinetic, thermodynamic and stability studies. J Colloid Interface Sci 454:52-60

57. Yang WY, Wen SX, Jin L, Rong L, Tetsuo M, Bo C (2006) Immobilization and characterization of laccase from Chinese Rhus vernicifera on modified chitosan. Process Biochem 41:1378-1382

Publisher's Note Springer Nature remains neutral with regard to jurisdictional claims in published maps and institutional affiliations. 